\title{
Thermal stress damage effect of matrix modified CFRP subjected to lightning
}

\author{
LI Bin ${ }^{1}$, CHANG Fei ${ }^{1}$, WEI Xiaolong ${ }^{1,}{ }^{*}$, XIAO Yao ${ }^{2,}{ }^{*}$, HE Weifeng ${ }^{1}$, Ming Yueke ${ }^{3}$, DONG Zhangzhi ${ }^{1}$ \\ ${ }^{1}$ Aeronautics Engineering College, Air Force Engineering University, Xi'an 710038, China \\ ${ }^{2}$ Aviation Maintenance NCO Academy, Air Force Engineering University, Xinyang, Henan 464031, China \\ ${ }^{3}$ State Key Laboratory for Manufacturing Systems Engineering, Xi'an Jiaotong University, Xi'an 710054, China
}

\begin{abstract}
Aiming at the carbon fiber reinforced plastics (CFRP) of poor electrical conductivity which will lead to thermal stress damage due to intense Joule effect under lightning strikes, electro-thermal-structure coupling models of CFRP lightning strikes were established. By analyzing the thermal strain, thermal stress and status of the modified and unmodified CFRP, their thermal expansion characteristics were compared. Compared with the unmodified CFRP, the thermal strain peak value of the modified CFRP is respectively increased by $36.33 \%, 53.92 \%, 66.62 \%$, and the thermal stress peak value of them is respectively reduced by $22.63 \%, 26.53 \%$, and $9.45 \%$ in the absence of dielectric breakdown. But in the breakdown state, both specimens appear complete delamination damage, the protective effect of matrix modification becomes invalid. The thermal stress damage is found having little effect on the damage morphology of the specimens after lightning strikes by comparing their CT images.
\end{abstract}

\section{Induction}

Composite material is the pioneer of aerospace structural material, and carbon fiber reinforced polymer (CFRP) is in the rapid development stage of application research. Thanks to its excellent mechanical properties, fatigue resistance, corrosion resistance and significant weight reduction effect, the application range of composite materials in the aviation field has gradually expanded, and even a fully composite aircraft has appeared [1-3]. It is normal for an aircraft to be struck by lightning during flight. The currently recognized probability is 1 time per 3000 hours. Because traditional metal components can form a good conductor by overlapping each other, the lightning current can be smoothly conducted away and the "Faraday cage" effect is produced so as to protect the airborne equipment [4-5]. Therefore, in the past, even if the aircraft was struck by lightning, the probability of safe survival of aircraft was very high; however, as resin-based composite materials are more and more widely used in aircraft, their short plates with poor electrical conductivity are gradually exposed, making it easier to suffer injury for aircraft to survive lightning[7].

At present, many scholars believe that the mechanism of lightning current's damage to CFRP mainly comes from the severe Joule effect produced by the lightning current. A large amount of heat is generated in this process, causing violent heating and ablation of CFRP, and a series of indirect effects including recoil effect caused by CFRP vaporization, thermal expansion effect caused by CFRP heating, etc. Of course, the overpressure impact, electromagnetic force and high temperature of the lightning current channel itself also play a secondary role[8-9]. Compared with the traditional copper mesh protection, the use of matrix modification and other methods to enhance the conductivity of composite materials is a new type of lightning protection method. Chakravarthi used nickelplated single-wall carbon nanotubes (Ni-SWNTs) to modify the bimar resin, When the added mass is $4 \%$, the resistivity of the resin is reduced by 10 orders of magnitude[10]. Jikui Zhang inserted a layer of carbon nanotube film between each layer of CFRP laminate, which made the multilayer conductive layer inside the laminate, which reduced the damage depth and damage area by $77.6 \%$ and $68.0 \%$ respectively, while the area and depth of silver plated CFRP laminates decreased by $66.1 \%$ and $92.0 \%$ respectively under the same current intensity[11]. Guadagno, Raimondo, etc. improved the flame retardancy and conductivity of epoxy resin by using modified fillers containing graphene and cage polysesquioxane (POSS), and weakened the decomposition of resin at high temperature[12]. At the same time, the formation of graphene conductive network was observed on the nano scale, but it has not been verified by lightning test. The modification of composite resin matrix by graphene, carbon nanotubes, silver powder and nickel plated carbon fiber powder is a new idea for lightning protection of composite materials. The research group of the author is also carrying out corresponding research.

Thermal stress is an important reason for delamination damage of CFRP under lightning current. The electrical thermal coupling analysis using finite

\footnotetext{
a Corresponding author: 2018020080@mail.bistu.edu.cn
} 
element method is the main method to simulate the lightning damage of CFRP, which has a good effect on the thermal ablation damage effect of CFRP under the action of lightning current; in fact, with the increase of lightning current intensity, the mechanical damage effects such as thermal expansion and vaporization recoil caused by material heating will become very significant. This paper is based on the electrical thermal structure coupling Methods: the delamination damage effect of matrix modified composites caused by thermal stress during lightning stroke was studied.

\section{Electric-thermal-structure coupled constitutive model}

\subsection{Electric conduction equation}

In electrical conductive materials, the electric field follows Maxwell's equation and charge conservation[13]:

$$
\int_{S} \boldsymbol{J} \cdot \boldsymbol{n} \mathrm{d} S=\int_{V} r_{c} \mathrm{nd} V
$$

Where $\mathrm{V}$ is any control volume, its surface is $\mathrm{s} ; \mathrm{n}$ is the external normal direction of $\mathrm{S}$; $\mathrm{rc}$ is the internal volume current; $\mathrm{J}$ is the current density, and its conduction follows Ohm's law:

$$
J=\boldsymbol{\sigma}^{\mathrm{E}} \cdot \boldsymbol{E}=-\boldsymbol{\sigma}^{\mathrm{E}} \cdot \frac{\partial \varphi}{\partial X}
$$

Where $\mathrm{E}$ is the electric field strength; $\varphi$ is the electric potential; $\sigma \mathrm{E}$ is the electric conduction matrix.

Substituting Equation (2) into Equation (1), we can get the following results:

$$
\int_{V} \frac{\partial \delta \varphi}{\partial X} \cdot \boldsymbol{\sigma}^{E} \cdot \frac{\partial \varphi}{\partial X} \mathrm{~d} V=\int_{S} \delta \varphi \boldsymbol{J} d S+\int_{V} \delta \varphi \cdot r_{c} d V
$$

\subsection{Thermal-electric conversion equation}

Under the action of Joule effect, electric energy Pec is converted into heat energy $\mathrm{Q}$, and its conversion equation is [7]

$$
Q_{v}=\eta_{v} P_{e c}=\eta_{v}(\boldsymbol{J} \cdot \boldsymbol{E})=\frac{\partial \varphi}{\partial X} \cdot \boldsymbol{\sigma}^{E} \cdot \frac{\partial \varphi}{\partial X}
$$

Where $\eta_{v}$ is the energy conversion coefficient.

\subsection{Heat-force transformation equation}

After the lightning current is attached to the composite, Joule heat is generated under the control of electrical thermal constitutive equation (1)-(4), which leads to the rise of material temperature, thermal expansion stress and thermal expansion strain []14:

$$
\left[\begin{array}{c}
\sigma_{11} \\
\sigma_{22} \\
\sigma_{33} \\
\sigma_{13} \\
\sigma_{23} \\
\sigma_{12}
\end{array}\right]=\left[\begin{array}{llllll}
C_{11} & C_{12} & C_{13} & & & \\
C_{12} & C_{22} & C_{23} & & & \\
C_{13} & C_{23} & C_{33} & & & \\
& & & C_{44} & & \\
& & & & C_{55} & \\
& & & & & C_{66}
\end{array}\right]\left[\begin{array}{c}
\varepsilon_{11}-\alpha_{1} \Delta T \\
\varepsilon_{22}-\alpha_{2} \Delta T \\
\varepsilon_{33}-\alpha_{3} \Delta T \\
\gamma_{13} \\
\gamma_{23} \\
\gamma_{12}
\end{array}\right]
$$

Where

$$
\begin{gathered}
C_{11}=\frac{1-v_{23} v_{32}}{E_{2} E_{3} \delta} \\
C_{12}=\frac{v_{21}+v_{31} v_{23}}{E_{2} E_{3} \delta} \\
C_{13}=\frac{v_{31}+v_{21} v_{32}}{E_{2} E_{3} \delta} \\
C_{22}=\frac{1-v_{13} v_{31}}{E_{1} E_{3} \delta} \\
C_{23}=\frac{v_{23}+v_{21} v_{13}}{E_{1} E_{3} \delta} \\
C_{33}=\frac{1-v_{12} v_{21}}{E_{1} E_{2} \delta} \\
C_{44}=G_{13} C_{55}=G_{23} C_{66}=G_{12} \\
1-v_{12} v_{21}-v_{23} v_{32}-v_{13} v_{31}-2 v_{21} v_{32} v_{13} \\
E_{1} E_{2} E_{3}
\end{gathered}
$$

Where $\sigma 11, \sigma 22$ and $\sigma 33$ are the normal stresses in $\mathrm{x}$, $\mathrm{y}$ and $\mathrm{z}$ directions respectively; $\sigma 13, \sigma 23$ and $\sigma 12$ are the shear stresses in the $\mathrm{x}-\mathrm{z}, \mathrm{y}-\mathrm{z}$ and $\mathrm{x}-\mathrm{y}$ planes respectively; $\mathrm{E} 1, \mathrm{E} 2$ and E3 are young's modulus in $\mathrm{x}, \mathrm{y}$ and $\mathrm{z}$ directions respectively; G13, G23 and G12 are the shear modulus of the material in the $x-z, y-z$ and $x-y$ planes respectively; $\alpha 1, \alpha 2$ and $\alpha 3$ are the thermal expansion coefficients in $\mathrm{x}, \mathrm{y}$ and $\mathrm{z}$ directions; and $\varepsilon 1, \varepsilon 2$ and $\varepsilon 3$ are positive strains in $\mathrm{x}, \mathrm{y}$ and $\mathrm{z}$ directions; $\gamma 13, \gamma 23$ and $\gamma 12$ are shear strains in $\mathrm{x}-\mathrm{z}, \mathrm{y}-\mathrm{z}$ and $\mathrm{x}-\mathrm{y}$ planes respectively; $v$ is Poisson's ratio; $\delta$ is strain; meanwhile, in order to ensure the convergence of calculation, the viscosity coefficient $\mu$ is set to $50 \mu \mathrm{s}$.

\section{Electrical-thermal-structure coupling model for CFRP suffering from lightning strike}

\section{1 model design}

Matrix modification protection is to improve the conductivity of CFRP by adding conductive filler into the resin matrix of CFRP, so as to achieve the purpose of lightning protection. According to ASTM D7137[15]. Two specimen models of unprotected CFRP laminates (Group A) and matrix modified protective CFRP laminates (Group B) were designed. The orders of laminates were both [45/-45/0/90/90/-45/0/45/0/90/$45 / 45] \mathrm{s}$, and the thickness of single layer was $0.15 \mathrm{~mm}$, and the size was $150 \mathrm{~mm} \times 100 \mathrm{~mm} \times 3.6 \mathrm{~mm}$. The appearance of the model is shown in Figure 1. 


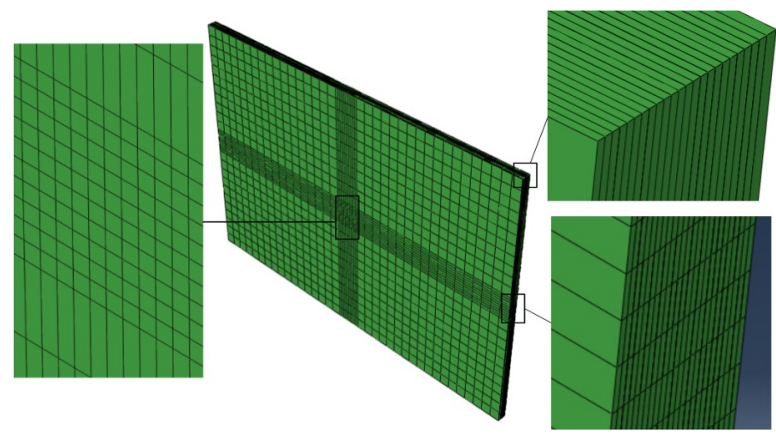

Fig.1 Model of the CFRP laminate

According to the dielectric breakdown of composite materials under lightning current, two kinds of finite element models of electrical thermal structure coupling under non breakdown state and breakdown state are established. Both of them contain 72865 nodes and 67680 elements, including 33120 zero thickness elements. However, the element types of the two models are different: $\mathrm{q} 3 \mathrm{~d} 8$ (hexahedral eight node electric thermal structure coupling) model in the non breakdown state In the breakdown state, the zero thickness interface type in the model is cohesive interface, which is composed of 33120 zero thickness elements of COH3D8 (hexahedral eight node cohesive force element), and the rest are $34560 \mathrm{q} 3 \mathrm{~d} 8$ elements. The zero thickness interface is shown in Figure 2.

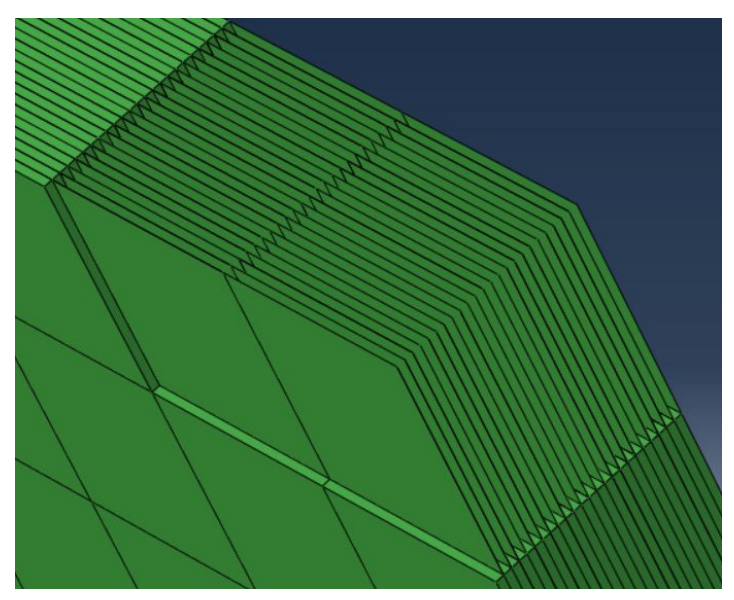

Fig.2 Interfaces without thickness

\subsection{Electrical and thermal properties of CFRP}

The matrix modified CFRP laminates were obtained by using the modification technology described in reference [16]. The change of electrothermal properties with temperature is shown in Table 1[18].

Table 1. Electric and thermal properties of matrix modified/unmodified CFRP

\begin{tabular}{ccccccc}
\hline \multirow{2}{*}{$T /{ }^{\circ} \mathrm{C}$} & $C_{\mathrm{p}} /\left(\mathrm{J} \cdot \mathrm{kg}^{-1} \cdot \mathrm{K}^{-1}\right)$ & \multicolumn{3}{c}{$\sigma /\left(\mathrm{S} \cdot \mathrm{m}^{-1}\right)$} & & $\lambda /\left(\mathrm{W} \cdot \mathrm{m}^{-1} \cdot \mathrm{K}^{-1}\right)$ \\
\cline { 3 - 7 } & & $\sigma_{\mathrm{x}}$ & $\sigma_{\mathrm{y}}$ & $\sigma_{\mathrm{z}}$ & $\lambda_{\mathrm{x}}$ & $\lambda_{\mathrm{y}, \mathrm{z}}$ \\
\hline \multirow{2}{*}{25} & 1065 & 29300 & $1200 /$ & $0.07 /$ & 11.8 & 0.609 \\
& & & 77.8 & 400 & & \\
300 & 2100 & 29300 & $1200 /$ & $0.07 /$ & 11.8 & 0.609 \\
600 & 1700 & 29300 & 2000 & 2000 & 1.736 & 0.1
\end{tabular}

\begin{tabular}{ccccccc}
1000 & 1900 & 29300 & 2000 & 2000 & 1.736 & 0.1 \\
2212 & 2509 & 29300 & 2000 & 2000 & 1.376 & 0.1 \\
3316 & 2509 & 29300 & 2000 & 2000 & 1.376 & 0.1 \\
$>3316$ & 5875 & $1 \times 10^{8}$ & $1 \times 10^{8}$ & $1 \times 10^{8}$ & 1.015 & 0.1 \\
\hline
\end{tabular}

Where $\mathrm{T}$ is temperature; $\rho$ is density; $\mathrm{Cp}$ is specific heat capacity; $\sigma \mathrm{x}, \sigma \mathrm{y}$ and $\sigma \mathrm{z}$ are conductivity along fiber direction, in-plane perpendicular to fiber direction and along thickness direction; $\lambda \mathrm{x}, \lambda \mathrm{y}$ and $\lambda \mathrm{z}$ are thermal conductivity along fiber direction, in-plane perpendicular to fiber direction and along thickness direction respectively. At $25^{\circ} \mathrm{C}, 300^{\circ} \mathrm{C}$ and $600^{\circ} \mathrm{C}$, the conductivity of modified CFRP and unmodified CFRP before and after "/" were respectively expressed. In the breakdown state, the insulation of the composite is lost, and the conductivity along the thickness direction is set as $20000 \mathrm{~S} / \mathrm{m}$.

The thermal expansion rate of CFRP changes at different temperatures, as shown in Table 2.

Table 2. Thermal expansion coefficient of CFRP at different temperatures

\begin{tabular}{cccc}
\hline$T /{ }^{\circ} \mathrm{C}$ & $\alpha_{\mathrm{x}} /\left({ }^{\circ} \mathrm{C}^{-1}\right)$ & $\alpha_{\mathrm{y}} /\left({ }^{\circ} \mathrm{C}^{-1}\right)$ & $\alpha_{\mathrm{y}} /\left({ }^{\circ} \mathrm{C}^{-1}\right)$ \\
\hline 25 & $1.8 \times 10^{-8}$ & $2.16 \times 10^{-5}$ & $2.16 \times 10^{-5}$ \\
200 & $5.4 \times 10^{-8}$ & $3.78 \times 10^{-5}$ & $3.78 \times 10^{-5}$ \\
3316 & $5.4 \times 10^{-8}$ & $3.78 \times 10^{-5}$ & $3.78 \times 10^{-5}$ \\
$>3316$ & 0 & 0 & 0 \\
\hline
\end{tabular}

Where $\alpha \mathrm{x}, \alpha y$ and $\alpha$ zare the thermal expansion coefficients of CFRP along the fiber direction, in-plane perpendicular to the fiber direction and along the thickness direction, respectively.

The thermal expansion of CFRP results in thermal stress. When the temperature reaches $600{ }^{\circ} \mathrm{C}$, the vaporization pyrolysis of resin matrix is completed, and only carbon fiber is left; therefore, the mechanical properties of the resin decrease sharply. Except for the tensile strength along the fiber direction, other strength parameters are close to failure. When the temperature reaches $3316{ }^{\circ} \mathrm{C}$, all mechanical properties of CFRP are invalid. The mechanical properties of CFRP at different temperatures are shown in Table 3.

Table 3 Mechanical properties of CFRP at different temperatures

\begin{tabular}{ccccccccc}
\hline & \multicolumn{3}{c}{$E / \mathrm{MPa}$} & & \multicolumn{3}{c}{$G / \mathrm{MPa}$} \\
\cline { 2 - 8 }$T /{ }^{\circ} \mathrm{C}$ & \multirow{2}{*}{$E_{\mathrm{x}}$} & $E_{\mathrm{y}}$ & $E_{\mathrm{z}}$ & $\mu_{\mathrm{yz}}$, & $G_{\mathrm{xy}}$ & $G_{\mathrm{xz}}$ & $G_{\mathrm{yz}}$ \\
\cline { 3 - 8 } & & & & & & & \\
\cline { 3 - 8 } & 13700 & 8200 & 8200 & & 4360 & 3000 & 4360 \\
25 & 13700 & 6560 & 6560 & & 3488 & 2400 & 3488 \\
300 & 13700 & 82 & 82 & 0.34 & 34.88 & 24 & 34.88 \\
600 & 13700 & 4.1 & 4.1 & & 1.744 & 1.2 & 1.744 \\
3316 & 12000 & 4.1 & 4.1 & & 1.744 & 1.2 & 1.744 \\
$>3316$ & 0 & 0 & 0 & & 0 & 0 & 0 \\
\hline
\end{tabular}

Where Ex, Ey and Ez are the elastic modulus of CFRP along the fiber direction, in-plane perpendicular to the fiber direction and along the thickness direction; $\mu x y$, $\mu y z, \mu x z$ are Poisson's ratios in the corresponding plane directions, showing isotropy; Gxy, Gyz and Gxz are the shear elastic modulus in the corresponding plane direction. 


\subsection{Damage initiation and evolution criteria}

In order to simulate the delamination failure of zero thickness interface, the damage criterion should be set. The maximum stress criterion was chosen as the damage initiation criterion.

$$
\operatorname{MAX}\left\{\frac{\left[\sigma_{n}\right]}{N_{\max }}, \frac{\sigma_{s}}{S_{\max }}, \frac{\sigma_{t}}{T_{\max }}\right\}=1
$$

Where

$$
\left[\sigma_{n}\right]= \begin{cases}\sigma_{n} & \sigma_{n}>0 \\ 0 & \sigma_{n}<0\end{cases}
$$

Where $\sigma \mathrm{n}, \sigma \mathrm{s}$ and $\sigma \mathrm{t}$ are the nominal stress in three directions, and Nmax, Tmax and Smax are the peak stress intensity in three directions respectively.

The power function criterion is chosen as the damage evolution criterion:

$$
\left(\frac{G_{\mathrm{I}}}{G_{\mathrm{IC}}}\right)^{\alpha}+\left(\frac{G_{\mathrm{II}}}{G_{\mathrm{IIC}}}\right)^{\beta}+\left(\frac{G_{\mathrm{III}}}{G_{\mathrm{IIIC}}}\right)^{\gamma} \geq 1
$$

Where $\alpha, \beta$ and $\gamma$ are power factors, usually taken as 2; GI, GII and GIII are respectively the energy released by mode I, II and III fracture at the leading edges during delamination propagation; GIC, GIIC and GIIIC are the fracture toughness of materials resisting mode I, II and III fracture respectively.

The interlaminar damage initiation parameters of CFRP at different temperatures are shown in Table 4[19].

Table 4. Mechanical properties of CFRP at different temperatures

\begin{tabular}{cccccc}
\hline & \multicolumn{2}{c}{$G /(\mathrm{N} / \mathrm{m})$} & \multicolumn{2}{c}{$\sigma_{\max } / \mathrm{Pa}$} & \multirow{2}{*}{$K_{\mathrm{I}}=K_{\mathrm{II}}=K_{\mathrm{III}}$} \\
\cline { 2 - 5 }$T /{ }^{\circ} \mathrm{C}$ & $G_{\mathrm{I}}$ & $G_{\mathrm{II}}=G_{\mathrm{III}}$ & $\sigma_{\mathrm{I}, \max }$ & $\begin{array}{c}\sigma_{\mathrm{II}, \max }= \\
\sigma_{\mathrm{III}, \max }\end{array}$ & \\
\hline 25 & $2.6 \times 10^{2}$ & $1.002 \times 10^{3}$ & $3.0 \times 10^{7}$ & $6.0 \times 10^{7}$ & $1.0 \times 10^{14}$ \\
200 & $2.6 \times 10^{2}$ & $8.0 \times 10^{2}$ & $2.4 \times 10^{7}$ & $4.8 \times 10^{7}$ & $3.0 \times 10^{13}$ \\
300 & $2.6 \times 10^{2}$ & $8.0 \times 10^{2}$ & $2.4 \times 10^{7}$ & $6.0 \times 10^{5}$ & $1.0 \times 10^{13}$ \\
600 & 26 & 80 & $2.4 \times 10^{3}$ & $3.0 \times 10^{3}$ & $5.0 \times 10^{10}$ \\
3316 & 1 & 1 & 1 & 1 & 1 \\
$>3316$ & 0 & 0 & 0 & 0 & 0 \\
\hline
\end{tabular}

Where GIC, GIIC and GIIIC represent the energy release rate of type I, type II and type III fracture respectively; $\sigma \mathrm{I}, \max , \sigma \mathrm{II}, \max$ and $\sigma \mathrm{III}, \max$ are the maximum fracture stress of mode I, II and III respectively; KI, KII, KIII are the fracture stiffness of mode I, II and III respectively.

\section{4 lightning current parameters}

According to the relevant SAE standards, the standard lightning current waveform D component is adopted. Composite materials are prone to dielectric breakdown under high current. Therefore, the lightning current peak strength under non breakdown state is set as 20KA, 40ka and $60 \mathrm{kA}$, and the lightning current peak strength under breakdown state is 200kA. There are two kinds of specimens in each group, i.e. unmodified matrix (Group

\begin{tabular}{|c|c|c|c|c|c|}
\hline$\underset{r}{\text { Numbe }}$ & $\begin{array}{c}\text { Wavefor } \\
\mathrm{m}\end{array}$ & $\begin{array}{c}\text { Peak } \\
\text { curren } \\
t\end{array}$ & $\begin{array}{l}\text { Breakdow } \\
\text { n state }\end{array}$ & $\begin{array}{c}\text { Interval } /\left(\mathrm{A}^{2} \cdot \mathrm{s}\right. \\
)\end{array}$ & $\begin{array}{c}\text { Charg } \\
\text { e /C }\end{array}$ \\
\hline $\begin{array}{l}\mathrm{A} 20, \\
\mathrm{~B} 20\end{array}$ & \multirow{4}{*}{ D } & 20 & No & 46316 & 4.13 \\
\hline $\begin{array}{l}\text { A40, } \\
\text { B40 }\end{array}$ & & 40 & No & 185267 & 8.26 \\
\hline $\begin{array}{l}\text { A60, } \\
\text { B60 }\end{array}$ & & 60 & No & 416851 & 12.38 \\
\hline $\begin{array}{l}\mathrm{A} 200 \\
\mathrm{~B} 200\end{array}$ & & 200 & Yes & 3546068 & 36.138 \\
\hline
\end{tabular}
A) and matrix modified (Group B), as shown in Table 5.
Table 5. Peak current of lightning and protection of specimens

\section{Results and analysis}

\subsection{Thermal expansion analysis of composite under non-breakdown state}

In the non-breakdown state, the degree of delamination damage can be judged by comparing and analyzing the thermal strain and thermal stress of the modified and unmodified specimens. Different from the modified materials, the anisotropy of the composite aggravates the stress-strain imbalance in the plane.

\subsection{1 thermal strain analysis}

Under one-dimensional condition, the thermal strain can be expressed as follows:

$$
\delta=\mathrm{a} \cdot l \cdot \Delta T
$$

Where $\delta$ is the thermal strain; a is the coefficient of thermal expansion; 1 is the initial size of the material; $\Delta \mathrm{T}$ is the temperature change.

Although the temperature rise range of the composite under the action of lightning current can reach several thousand degrees Celsius, due to the small initial size of the specimen, it can be found from Table 2 and Equation (17) that the thermal strain of the specimen is small, so it is impossible to directly observe the thermal expansion morphology of the specimen. The temperature field of specimen with 1000 times deformation coefficient is shown in Fig. 3.

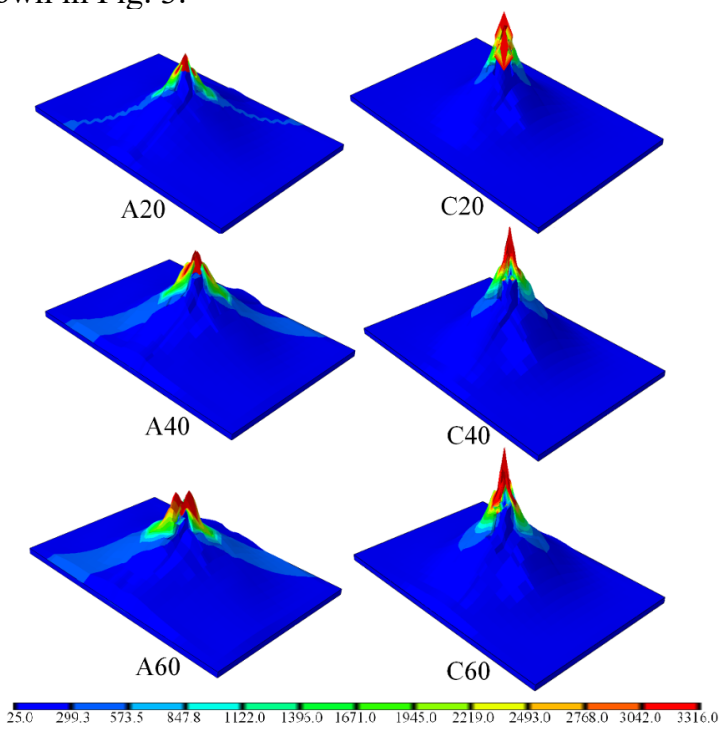

Fig.3 Temperature fields of specimens with deformation coefficient of 1000 times 
It can be found that: the thermal expansion morphology of the specimen is consistent with the distribution pattern of the temperature field. The uplift area of the unprotected specimen is significantly larger than that of the matrix modified specimen under the same current intensity, but the uplift height is lower than that of the matrix modified specimen, which is consistent with the temperature field distribution characteristics of the matrix modified specimen with the decrease of ablation area and the increase of ablation depth. Therefore, from the morphology point of view, although the matrix modification effectively reduces the thermal expansion area of the composite, it also increases the thermal expansion degree in the thickness direction of the lightning current attachment area. The thermal strain can be analyzed more accurately by cutting the strain field along the symmetry plane. The cross section of the strain field under 100 times of deformation coefficient is shown in Fig. 4.

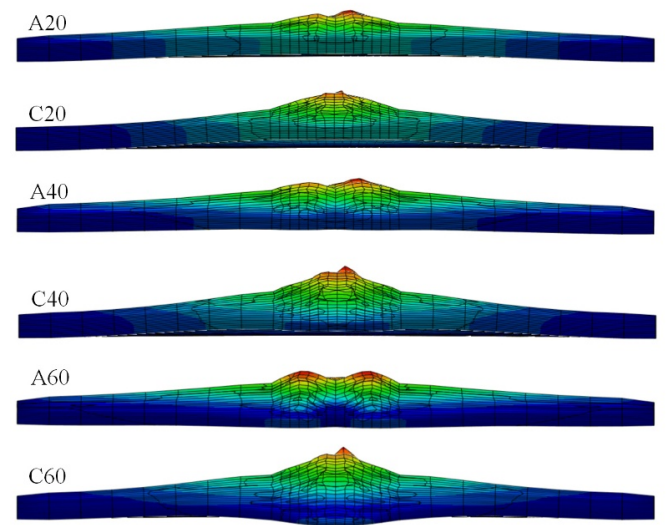

Fig.4 Strain field tomographic images of specimens with deformation coefficient of 100 times

The deformation region is concentrated in the upper part of the specimen, and the strain of the element gradually increases with the approach to the upper surface, which is mainly due to the accumulation effect of thermal strain. Meanwhile, it can be found that the cumulative effect can be transferred to the bottom surface of the material through the B60 specimen, which indicates that the delamination damage of the composite can not only appear in the upper part of the specimen, but also can be conducted through stress and strain The thermal stress damage of the lower surface area of the specimen is caused. The thermal strain peak value of the specimen is analyzed quantitatively, as shown in Fig. 5.

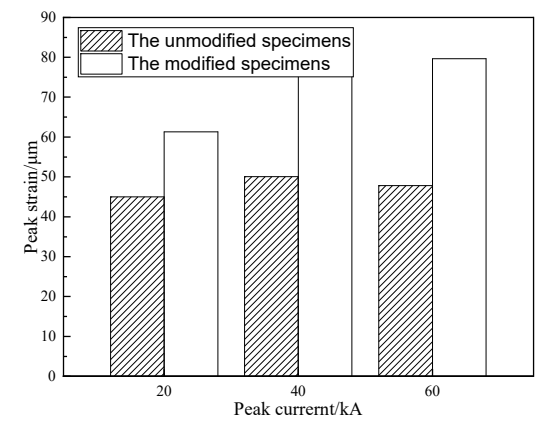

Fig.5 Peak thermal strain
At the same current strength, the maximum strain of modified specimens is significantly greater than that of unmodified specimens, and the peak values of thermal strain of specimens B20, B40 and B60 are 36.33\%, $53.92 \%$ and $66.62 \%$ higher than those of specimens A20, A40 and A60 respectively. The main reason is that the ablation depth of modified specimens is deeper[20], which results in more intense thermal expansion of inner layers and stronger accumulative effect on upper surface. By comparing the maximum thermal expansion rate of the two groups of specimens, it can be found that the thermal expansion effect of matrix modification on composites and the aggravation of delamination damage are more significant, and the aggravation effect becomes stronger with the increase of current.

\subsubsection{Thermal stress analysis}

Thermal stress is the direct cause of delamination damage caused by thermal expansion of composite materials caused by lightning stroke, and its distribution and change are consistent with and different from thermal strain. The stress fields on the surfaces of the two groups of specimens at the end of the lightning strike are shown in Fig. 6.
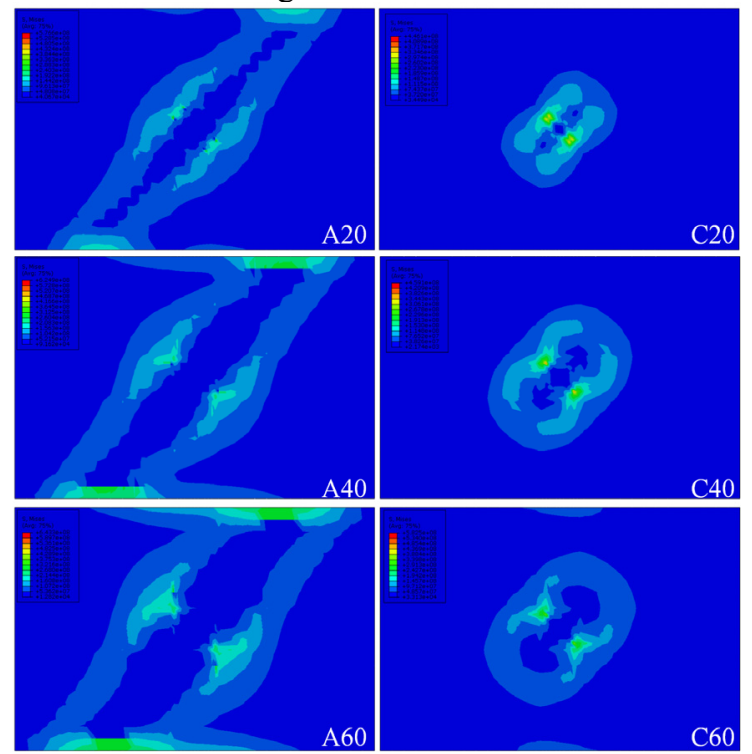

Fig.6 Surface stress fields of specimens at the end of the lightning strike

At the end of the lightning strike, the high stress area is concentrated at the boundary of the ablation area and the thermal stress is induced at the edge of the specimen by conduction due to the full degree of freedom fixed restraint at the edge of the specimens. Compared with the peak value of thermal strain, the relationship between the peak value of thermal stress of two groups of specimens is reversed. At the end of lightning stroke, the peak value of thermal stress of two groups of specimens is shown in Fig. 7. 


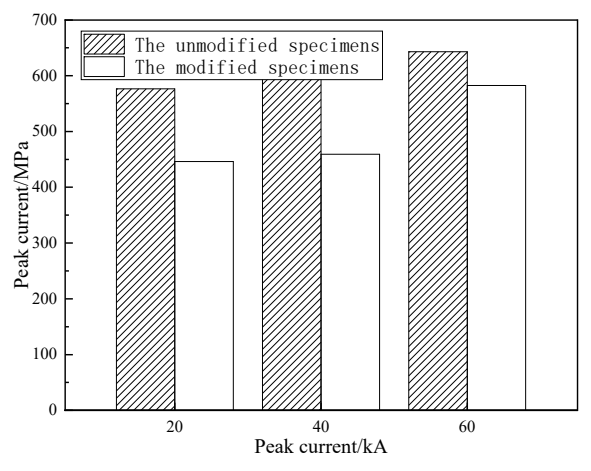

Fig.7 Peak thermal stress

The stress level of unmodified specimens is significantly higher than that of modified specimens. The peak stress values of B20, B40 and B60 specimens are $22.63 \%, 26.53 \%$ and $9.45 \%$ lower than those of A20, A40 and A60 specimens respectively. The main reason is that the anisotropy difference of conductivity of unmodified specimens is more intense, which leads to more uneven thermal expansion along all directions in the ablation area and more serious stress concentration. Resulting in higher stress peaks.

\subsubsection{Protective effect of matrix modification without breakdown}

According to the different characteristics of matrix modified and unmodified composites during lightning stroke, the lightning protection effect of matrix modified composites can be analyzed by combining the change of stress distribution in the thickness direction. During lightning strike, the high stress area in the pavement presents a circular distribution and gradually diffuses with the expansion of ablation area, and the high stress area close to the interior gradually transforms into the low stress area. The distribution of the high stress area in the thickness direction is similar: with the deepening of ablation damage, the high stress area in the surface layer gradually transforms into the low stress area, but the thermal stress damage caused at this time is irreversible. The stress field at the end of lightning strike is taken as the reference standard for evaluating thermal expansion delamination of composite materials because the high stress area of composite materials reaches the deepest and the widest range at the end of the lightning strike. The distributions of stress fields at the end of lightning strikes for A20 and B20, A40 and B40 are shown in Fig. 8 .

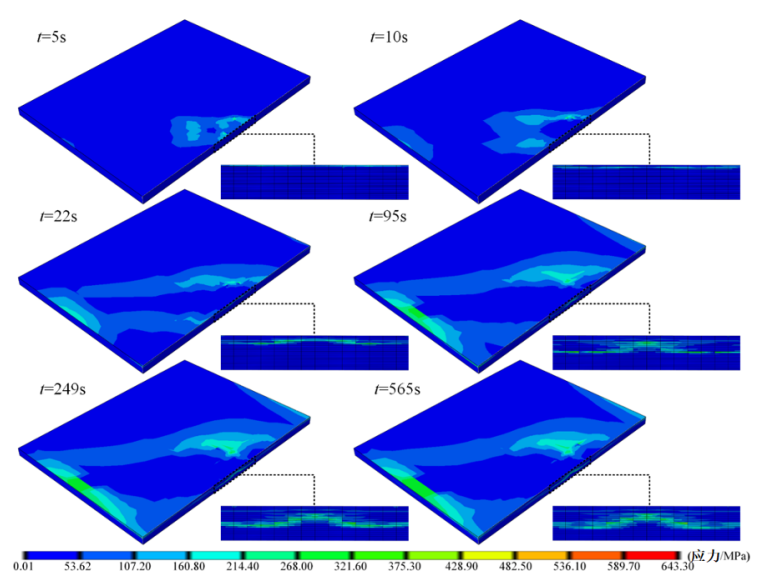

(a) A60

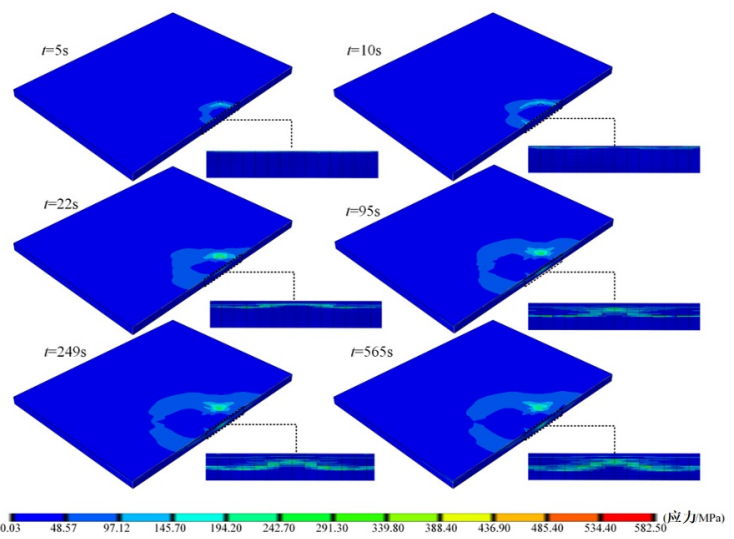

(b) B60

Fig.8 Temperature fields of A60 and C60 at the end of lightning strike

By using the same method to analyze other specimens, it is found that the high stress zones of A20, $\mathrm{A} 40$ and $\mathrm{A} 60$ reach the 8th, 13th and 15th layers respectively, and $\mathrm{B} 20, \mathrm{~B} 40$ and $\mathrm{B} 60$ correspond to the 12 th, 15th and 16th layers respectively. It is consistent with the change of protective characteristics of high temperature ablation damage. Although the modified matrix protection significantly reduces the area of high stress zone and reduces the peak stress, it will deepen. The depth of the high stress zone results in deeper delamination damage.

\subsection{4 experimental result}

Industrial CT was used to scan the damaged areas of the matrix modified and unmodified specimens, as shown in Fig.

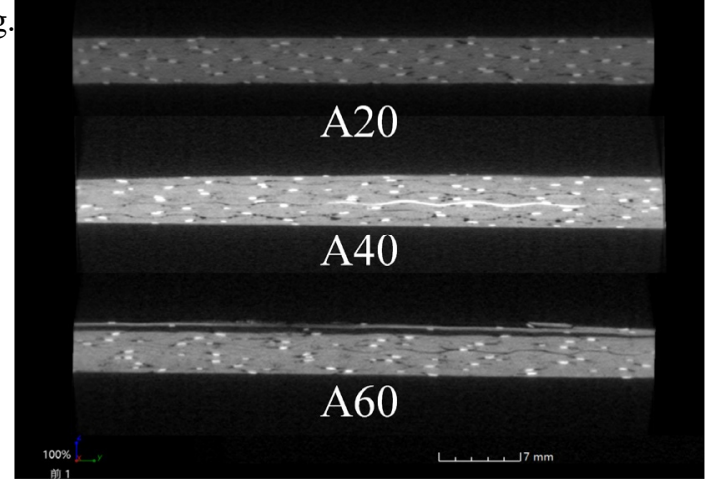




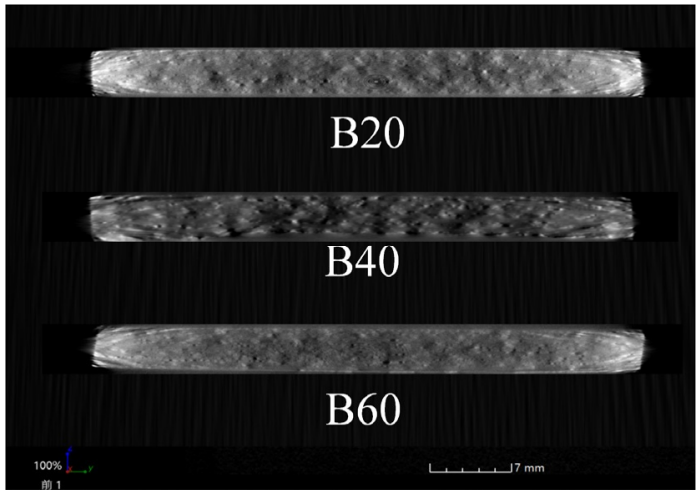

Fig.9 CT images of specimens

Through CT images, it can be found that the thermal expansion has little effect on the internal damage morphology of the specimens, and there is no significant difference between the matrix modified and unmodified specimens. The reasons include that the thermal expansion of the specimen is small, the specimen has cooled to room temperature during scanning, and part of the resin matrix melted by heating has solidified.

\subsection{Delamination damage in breakdown state}

Due to the introduction of zero-thickness cohesion unit in the breakdown model, the delamination damage caused by lightning stroke can be directly observed and analyzed. The cloud diagram of state variables of specimen A200 and B200 under breakdown state is shown in Fig. 10.

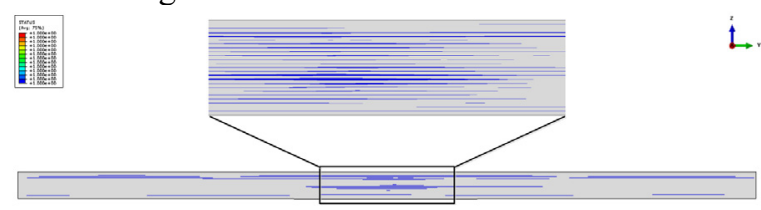

(a) A200

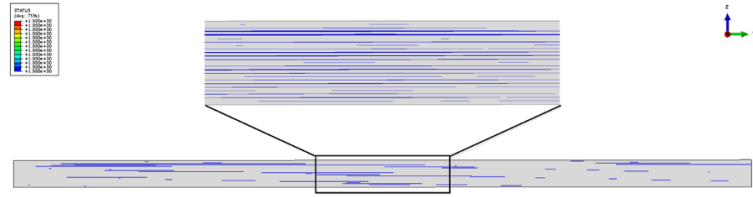

(b) B200

Fig.10 Status of the specimens in the breakdown state

Severe delamination damage occurred in both modified and unmodified specimens and separation of cohesion units between the layers occurred. It shows that only the thermal stress between the layers can cause the complete delamination damage of the composites under the breakdown state. If other factors such as impact force of lightning current channel itself are considered, the complete delamination damage of the composites will be more significant. Therefore, when dielectric breakdown occurs in composites, the protective effect of matrix modification on thermal stress failure will fail.

\section{Conclusion}

The electro-thermal-structural coupling simulation study on thermal expansion delamination damage of unprotected and matrix modified protective specimens caused by lightning current is carried out. Zero-thickness cohesion unit is introduced and its stress field, strain field and state variable are analyzed. The main conclusions are as follows:

1. Composite material heats up sharply under the action of electric current, and its thermal strain is caused by thermal expansion effect, which then generates thermal stress, resulting in lightning strike delamination damage of material; the temperature field under the action of lightning current plays a decisive role in its stress field, strain field and final damage.

2. Thermal strain of composites has cumulative effect. Thermal strain of inner layer will accumulate to surface layer, resulting in maximum thermal strain of surface layer; anisotropy of unmodified material is stronger, resulting in more anisotropic distribution of temperature field, more likely to produce stress concentration and higher peak value of thermal stress.

3. During lightning stroke, the high stress area of composites does not concentrate in the high temperature area, but in the high-low temperature junction area with large gradient of temperature change; with the expansion of high temperature ablation area, the high stress area gradually expands in a ring, which causes the stress level in some areas to change from low stress to high stress and then to low stress.

4. Under the condition of lightning current peak value of $20 \mathrm{kA}, 40 \mathrm{kA}$ and $60 \mathrm{kA}$, the thermal strain peak value of the matrix modified composite material increases $36.33 \%, \quad 53.92 \%, \quad 66.62 \%$ respectively compared with the unmodified composite material, and the thermal stress peak value decreases $22.63 \%, 26.53 \%$, $9.45 \%$ respectively. Although the matrix modification reduces the area of high stress area of the specimen and reduces the stress concentration level, it increases the thermal expansion in the thickness direction.

5. When dielectric breakdown occurs, both modified and unmodified specimens have severe delamination, and the protective effect of matrix modification is ineffective at this time; even if other external factors such as impact force of lightning current channel are not considered, only thermal stress is sufficient to cause complete delamination damage of composites under breakdown state.

\section{References}

1. DU S. Advanced composite materials and aerospace engineering $[\mathrm{J}]$. Acta Materiae Compositae Sinica,2007, 24(1): 1-12.

2. YI X., CAO Z., Li H., et al. Aeronautical composite technology [M]. Beijing: Aviation industry press, 2013:3-14.

3. CHRISTOS K. Design and Analysis of Composite Structures: With Applications to Aerospace Structures[M].1st ed. New Jersey: John Wiley\&Sons Ltd,2013:1-17.

4. LI B., CHANG F., XIAO Y., et al. Lightning damage effects of carbon fiber reinforced resin 
modified by silver powder [J]. Acta Materiae Compositae Sinica, 2020, 37.

5. Vipin K., Tomohiro Yokozeki, Christian Karch, et al. Factors affecting direct lightning strike damage to fiber reinforced composites: A review $[\mathrm{J}]$. Composites Part B: 2020(183).

6. Ogasawara T., Hirano Y, Yoshimura A. Coupled thermal-electrical analysis for carbon fiber/epoxy composites exposed to simulated lightning current $[\mathrm{J}]$. Composites Part A Applied Science \& Manufacturing, 2010, 41(8):0-981.

7. YAO X., SUN J., et al. Damage Simulation and Experiment of Carbon Fiber Composites Subjected to Lightning Current[J]. High Voltage Engineering, 2017, 43(5):1400-1408.

8. Z.Q. Liu, Z.F. Y ue, F.S. Wang, Y.Y. Ji. Combining analysis of coupled electrical-thermal and BLOWOFF impulse effects on composite laminate induced by lightning strike. Applied Composite Materials, Published online: June 11, 2014.

9. Liu Z. Study on the Electric-Magnetic-ThermalStructure Coupling Effect of Composite Laminates in Lightning Environment[D]. Northwestern Polytechnical University, 2015.

10. Chakravarthi D K, Khabashesku V N, Vaidyanathan $\mathrm{R}$, et al. Carbon Fiber-Bismaleimide Composites Filled with Nickel-Coated Single-Walled Carbon Nanotubes for Lightning-Strike Protection[J]. advanced functional materials, 2011, 21(13):25272533.

11. Zhang J, Zhang X, Cheng X, et al. Lightning strike damage on the composite laminates with carbon nanotube films: Protection effect and damage mechanism $[\mathrm{J}]$. Composites Part B Engineering, 2019, 168:342-352.

12. Guadagno, L., Vertuccio, et al.Electrical current map and bulk conductivity of carbon fiberreinforced nanocomposites[J]. Polymers2019(11).

13. Raimondo M, Guadagno L, Speranza V, et al. Multifunctional graphene/POSS epoxy resin tailored for aircraft lightning strike protection[J]. Composites, 2018, 140b(may):44-56.

14. WANG D., HE J., LIU K.. Thermo-mechanical coupling analysis of composite case during cooling process after cured[J]. Journal of Solid Rocket Technology:1-9[2020-05-11].

15. ASTM D7137 / D7137M - 12 Standard Test Method for Compressive Residual Strength Properties of Damaged Polymer Matrix Composite Plates[J]. 2012.

16. XIAO Y., LI S., CHANG F., et al. Conductive epoxy resin for modified carbon fiber composite laminated board[P]. China Patent, ZL 201810727193.9,2019-01.11.

17. Abdelal G, Murphy A. Nonlinear numerical modelling of lightning strike effect on composite panels with temperature dependent material
properties[J]. Composite Structures, 2014, 109(mar.):268-278.

18. Zaman W, Li K Z, Ikram S, et al. Morphology, thermal response and anti-ablation performance of 3D-four directional pitch-based carbon/carbon composites[J]. Corrosion Science, 2012, 61: 134142

19. K. $\mathrm{Fu}$, et al. Modelling of lightning-induced dynamic response and mechanical damage in CFRP composite laminates with protection[J]. Composite Structures, 2019.

20. Xiao Yao, Li Shulin, Wang Yupian, etc. Effects of conductivity of composite materials on the extent of lightning ablation damage [J]. Journal of Aviation Materials, 2018, 38 (005): 123-131. 